$\xi=-1$

\title{
Experimental Behaviour of Sandwich Panels Using Copper Slag Mortar
}

\author{
Dr.Lavanya Prabha.S ${ }^{\mathrm{a}}$, Dr.Neelamegam ${ }^{\mathrm{b}}$,Vinodhini Sri.R ${ }^{\mathrm{c}}$. \\ ${ }^{a}$ Professor \& Head, Easwari Engineering College, Department of Civil Engineering, Chennai Tamil Nadu, India. \\ ${ }^{b}$ Assistant Professor, Easwari Engineering College, Department of Civil Engineering, Chennai Tamil Nadu, India. \\ ${ }^{c}$ Post Graduate Studnent, Easwari Engineering College, Department of Civil Engineering, Chennai Tamil Nadu, India.
}

\begin{abstract}
This paper presents the study to investigate the viability of using copper slag as fine aggregate in cement mortar. Two series of cement mortar mixtures were prepared with different proportion of copper slag at different workability. In the first series, various proportions of copper slag is substituted for sand ranging from $0 \%$ to $100 \%$ with constant workability. Second series consists of fully replaced copper slag for sand in the cement mortar, which was achieved by maintaining the same workability as that of the control mortar mixture from first series and a control mixture for this new workability with sand as fine aggregate. The strength of twelve trial cement mortar mixtures were tested. The results indicate high compressive strength upto $50 \%$ replacement of copper slag, after that the compressive strength decreases with increase in copper slag percentage in cement mortar. The copper slag content in the mortar adversely affected the compressive strength of the mortar mixtures as $4.2 \%$ and $21.1 \%$ improvement in the compressive strength of the cement mortar for 50\% replacement compared and 100\% replacement compared with the control mortar mixtures. The density of cement mortar increases with increase in copper slag. From these trial mixtures two optimized mixtures were selected and were used to cast the sandwich panels. This panels were tested for flexural behaviour and axial load compression behaviour. The behavior of sandwich panels were simulated using ANSYS and the results were compared with experimental results.
\end{abstract}

Keywords: Industrial Waste, Cement Mortar, Copper Slag, Workability, Ferrocement Panels.

\section{Introduction}

Major problems during the construction of a structure are the availability of the building materials. These building materials were non-renewable resources, which include sand, gravels, etc. Hence, it is necessary to explore other resources that have similar properties as fine aggregate. In India, about 6-6.5 million tons of copper slag are generated annually. Copper slag is a by-product obtained from the copper refining industry. The disposal of copper slag in landfills is not a correct option due to environmental problems, lack of land, etc. Copper slag as a partial and full substitution for fine aggregate and coarse aggregate have been mentioned in many works $[1,3,4,5]$. Many researchers have been carries out to investigate the usage of copper slag as fine aggregate and coarse aggregate in mortar and concrete. The mechanical properties of mortar and concrete are also investigated in several research works. Previous researches also suggest that copper slag is a beneficial utilization of industrial by-product in improvement of properties of mortar and concrete. Cement mortar shows a continuous increase in the density as the copper slag content increases. In this paper, copper slag was used as a substitution for sand. As the copper slag percentage increases, the workability also increases. Some researchers showed that a substitution of $50 \%$ copper slag yielded more compressive strength than the other mixtures and control mortar mixtures. The water absorption rate of copper slag is less compared to the sand. Several studies proved that copper slag can be used as a substitution for fine aggregate in order to achieve mortar with better mechanical and durability properties.
This paper presents the effect of using copper slag as fine aggregate in cement mortar for developing ferrocement sandwich panels. Another series of cement mortar is prepared by maintaining the workability as that of the control mixture. Ferrocement is a versatile form of reinforced concrete, made up of meshes, cement, sand and finally water that shows unique qualities of strength, serviceability and durability. Ferrocement techniques relatively allow us to have slender size components and can be done by the unskilled labour. Sandwich ferrocement panels are eco-friendly, sound insulation, fire resistance, and less wastage of material during construction compared to conventional reinforced concrete. In this study, sandwich panels where cast using the optimized mixtures. The experimental investigation showed that the behaviour of panels developed by $50 \%$ substitution of copper slag shows better results than the control mixture panel.

\section{Objective}

In previous research work $[1,3,4,5,7,8,11,15]$ the authors discusses the performance of copper slag substitution as fine aggregate on the compressive strength, durability, and workability of concrete. Concrete of different mixture proportions of copper slag were prepared and the specimens were tested to know the characteristics of the concrete at different curing ages. The investigation showed that the density of concrete increases. The main objective of this paper is to prepare panels using a mortar mixture, where the natural resources were $100 \%$ replaced by the industrial waste 
copper slag. That helps in fast construction of low cost construction buildings.

\section{Materials}

\subsection{Cement}

The cement used in the study was Portland pozzolana cement (PPC) purchased from Ultratech Company. This cement is the most widely used in the construction industry in India.

\subsection{Fine Aggregate}

River sand is used as fine aggregate in this work. Sand is used normally as fine aggregate in mortar and concrete. Sand and Copper slag used were tested for gradation and they met specification requirements. The sand used in this project were sieved through $4.75 \mathrm{~mm}$ sieve.

\subsection{Copper Slag}

Copper slag was brought from Sterlite industry. The copper slag used was sieved through $4.75 \mathrm{~mm}$ sieve. Sieve analysis for both sand and copper slag were conducted in accordance with IS 3831970. Specific gravity and water absorption tested were conducted in accordance with IS 2386(part 3)-1963. The gradation curves for both sand and copper slag are presented in Fig.1. Both sand and copper slag satisfies the grading limit zone II. Properties of fine aggregate are presented in Table 1.

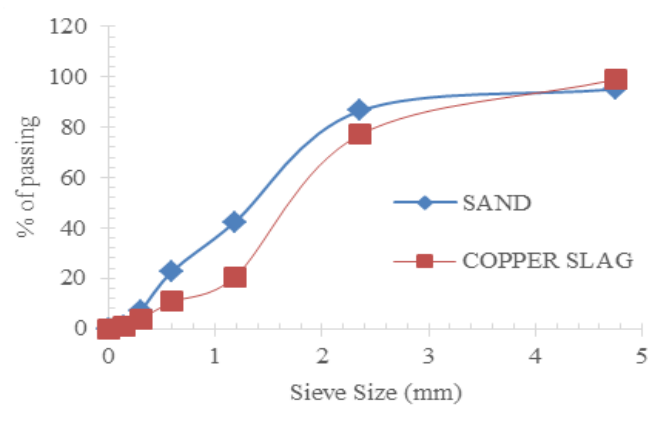

Fig. 1. Gradation curve of fine aggregate

Table 1: Properties of sand and copper slag

\begin{tabular}{|c|c|c|c|}
\hline Property & Material & & Value \\
\hline \multirow{2}{*}{ Specific gravity } & Sand & & 2.66 \\
\hline & Copper slag & & 3.50 \\
\hline \multirow{2}{*}{ Bulk density } & Sand & & $1647 \mathrm{~kg} / \mathrm{m}^{3}$ \\
\hline \multirow{2}{*}{ Water absorption } & Copper slag & & $2197 \mathrm{~kg} / \mathrm{m}^{3}$ \\
\hline & Sand & & $3.25 \%$ \\
\hline \multirow{2}{*}{ Fineness modulus } & Copper slag & & $1.395 \%$ \\
\hline & Sand & & 2.55 \\
\hline & Copper slag & & 2.12 \\
\hline
\end{tabular}

\section{Experimental Investigation}

\subsection{Cement Mortar}

The mix proportion chosen for this work is 1:2 cement mortar. The effect of using copper slag as a replacement of sand can be studied by preparing specimen of different proportions of copper slag ranging from $0 \%$ to $100 \%$ as shown in Table 2 . Total of nine specimens of size $100 \times 100 \times 100 \mathrm{~mm}$ dimensions cast for each proportion and three samples for each mixture were tested after the curing ages of 7,14 and $28^{\text {th }}$ day. The slump value of the cement mortar was determined to ensure the workability of the cement mortar. For the binder part, cement was used. The slump values of cement mortar are presented in Table 3.
Table 2: Mixture proportion

\begin{tabular}{|c|c|c|c|c|c|c|}
\hline $\begin{array}{c}\text { Sample } \\
\text { ID }\end{array}$ & Mix ratio & & Sand & Copper slag & w/b ratio \\
\hline A0 & $1: 2$ & & $100 \%$ & - & & 0.4 \\
\hline A1 & $1: 2$ & & $90 \%$ & $10 \%$ & & 0.4 \\
\hline A2 & $1: 2$ & & $80 \%$ & $20 \%$ & & 0.4 \\
\hline A3 & $1: 2$ & & $70 \%$ & $30 \%$ & & 0.4 \\
\hline A4 & $1: 2$ & & $60 \%$ & $40 \%$ & & 0.4 \\
\hline A5 & $1: 2$ & & $50 \%$ & $50 \%$ & & 0.4 \\
\hline A6 & $1: 2$ & & $40 \%$ & $60 \%$ & & 0.4 \\
\hline A7 & $1: 2$ & & $30 \%$ & $70 \%$ & & 0.4 \\
\hline A8 & $1: 2$ & & $20 \%$ & $80 \%$ & & 0.4 \\
\hline A9 & $1: 2$ & & $10 \%$ & $90 \%$ & & 0.4 \\
\hline A10 & $1: 2$ & & - & $100 \%$ & & 0.4 \\
\hline B1 & $1: 2$ & & $100 \%$ & - & & 0.37 \\
\hline B2 & $1: 2$ & & - & $100 \%$ & & 0.37 \\
\hline
\end{tabular}

Table 3: Slump value

\begin{tabular}{|c|c|c|}
\hline Sample ID & Water binder ratio & Slump value \\
\hline A0 & 0.4 & $60 \mathrm{~mm}$ \\
\hline A5 & 0.4 & Collapse \\
\hline B1 & 0.37 & True slump \\
\hline B2 & 0.37 & $62 \mathrm{~mm}$ \\
\hline
\end{tabular}

\subsection{Sample Preparation}

All the dry ingredients required for the mixtures were taken by weight basis and are kept in an individual container. Normal tilting type mixture machine of capacity $80 \mathrm{Kg}$ was used for preparation of mortar mixtures. The weighed ingredients were dry mixed thoroughly, the required water quantity as poured into the mixture. Mixtures were mixed to get uniform color and consistency. The workability of the mixtures was checked using the slump cone test. Test specimens of size $100 \times 100 \times 100 \mathrm{~mm}$ were selected. Cement mortar specimens were compacted in three layers using tamping rod. Specimen were removed after 24 hours of room temperature drying from moulds and cured in the water tanks for testing ages of 7,14 and $28^{\text {th }}$ day. Another mixture B2 is prepared with maintaining the slump value same as that of the A0 mixture and the water cement ratio found to be of 0.37. To compare the B2 mixture another control mixture of 0.37 water cement ratio is also prepared.

\subsection{Testing Procedure.}

Compressive strength test was carried out on $100 \mathrm{~mm}$ cube specimen in UTM. All the specimens were tested in saturated surface dry condition before conducting the test. Compressive strength test was conducted on cement mortar cubes at 7, 14 and 28th day. Based on the test result of trial mixtures, three mixtures were optimized (A0, A5 and B2) were used to cast the panels. The compressive strength of trial mixtures were shown in Table 4.

From the above result, it is clear that A5 mixture shows $4.4 \%$ higher value than the A0 mixture. B2 mixture shows $26.7 \%$ \& $7.5 \%$ higher value than that of $\mathrm{A} 0$ mixture and B1 mixture. Hence, the mixtures A5 and B2 were optimized to cast panels.

Table 4: Compressive strength of trial mixtures

\begin{tabular}{|c|c|c|c|c|}
\hline \multirow{2}{*}{ Mix id } & \multicolumn{3}{|c|}{ Compressive strength } & \multirow{2}{*}{$\begin{array}{c}\text { Density } \\
\mathbf{K g} / \mathbf{m}^{\mathbf{3}}\end{array}$} \\
\cline { 2 - 4 } & $\mathbf{7}^{\text {th }} \mathbf{d a y}$ & $\mathbf{1 4}^{\text {th }} \mathbf{d a y}$ & $\mathbf{2 8}^{\text {th }} \mathbf{d a y}$ & 2168 \\
\hline A0 & 22.6 & 29.0 & 38.6 & 2170 \\
\hline A1 & 21.6 & 31.5 & 39.2 & 2195 \\
\hline A2 & 18.5 & 26.5 & 32.3 & 2347 \\
\hline A3 & 16.7 & 21.1 & 28.4 & 2494 \\
\hline A4 & 19.5 & 22.4 & 28.3 & 2545 \\
\hline A5 & 21.4 & 36.7 & 40.3 & 2571 \\
\hline A6 & 20.7 & 26.3 & 30.4 & 2653 \\
\hline A7 & 19.4 & 21.4 & 28.3 & 2673 \\
\hline A8 & 18.5 & 20.5 & 24.1 & 2710 \\
\hline A9 & 11.7 & 20.0 & 23.0 & 2745 \\
\hline A10 & 11.8 & 17.7 & 22.5 & \\
\hline
\end{tabular}




\begin{tabular}{|l|l|l|l|l|}
\hline B1 & 29.5 & 31.2 & 45.5 & 2174 \\
\hline B2 & 26.1 & 34.2 & 48.9 & 2737 \\
\hline
\end{tabular}

\section{Panels}

\subsection{Introduction}

Many researches [2, 6, 9, and 16] have studied the behaviour of panels and the dimension selected for this work is 900X600X100mm. Two different meshes of grid size $60 \times 60 \mathrm{~mm}$ and galvanized mesh of size $12 \mathrm{mmX} 12 \mathrm{~mm}$ were tied together using binding wire in a box shaped structure, which act as a reinforcement. This wire mesh were bent at the edges to the dimension of $870 \times 570 \times 70 \mathrm{~mm}$. thermocol of the same size were kept inside this reinforcement. A U-bend shaped meshes was provided at the center which connects the bottom meshes with top meshes to act as single unit as shown in Fig 2.

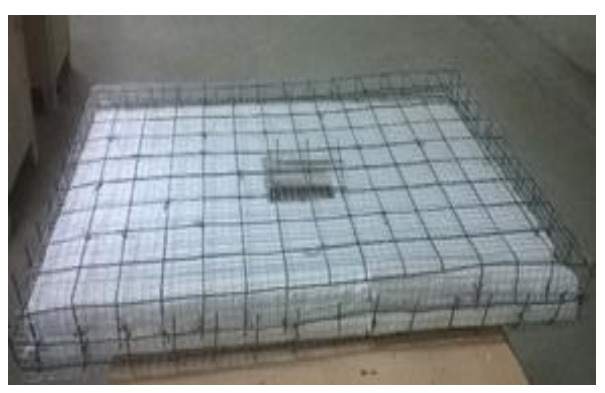

Fig. 2. Mesh reinforcement

In the wooden mould of dimension 900X600X100mm, a cover block of $15 \mathrm{~mm}$ thickness was used. The mortar was poured upto $15 \mathrm{~mm}$ as bottom layer. This mortar is well compacted manually. The bottom layer mesh was kept on this cement mortar and compacted uniformly, thermocol was inserted into the bottom layer mesh. Care was taken to flow mortar at the sides to form a single box unit. The top layer mesh is tied together with the bottom layer using binding wire. The top surface is smoothly finished. After 24 hours the panels was demoulded from the wooden mould and cured using gunny bags for 28 days.

\subsection{Test Setup}

After 28 days of curing, panels were surface dried and were whitewashed. Marking were drawn to the center of panels along length and breadth directions and a span of $800 \mathrm{~mm}$ were marked. A roller of width length $600 \mathrm{~mm}$ was kept at the centerline. The flexural strength test setup is shown in Fig 3. LVDT and demec gauge were used to calculate deflection and strain in the panels. Load was applied gradually in control manner. Demec points were used to measure the strain on the test specimens at $5 \mathrm{~mm}$ from top surface and $5 \mathrm{~mm}$ from bottom surface. The flexural strength of panels can be seen in Table 5 .

\begin{tabular}{|c|c|c|}
\multicolumn{4}{|c}{ Table 5: Flexural strength of panels } \\
\hline Mix id & $\begin{array}{c}\text { Average load } \\
(\text { KN) }\end{array}$ & $\begin{array}{c}\text { Average Flexural strength } \\
\left(\mathbf{N} / \mathbf{m m}^{\mathbf{2}}\right)\end{array}$ \\
\hline A0 & 21.5 & 4.3 \\
\hline A5 & 30.2 & 6.0 \\
\hline B2 & 32.0 & 6.4 \\
\hline
\end{tabular}

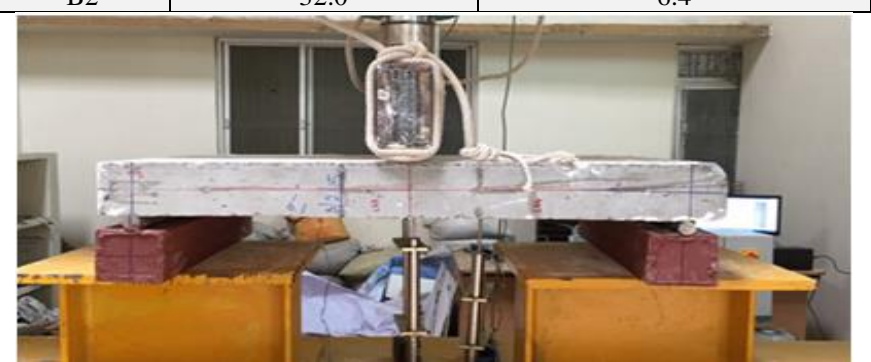

Fig. 3. Flexural strength test setup

It is interesting to note that the flexural strength of A5 mixture shows $40.2 \%$ higher value than the A0 mixture. B2 mixture shows $48.8 \%$ higher value than the $\mathrm{A} 0$ mixture.

\subsection{Load - Deflection Behaviour}

The average load delfection curve for A0 and A5 mixture with water cement ratio of 0.4 is shown in Fig 4. The load deflection curve for B2 mixture with water cement ratio 0.37 is represented in Fig 5.

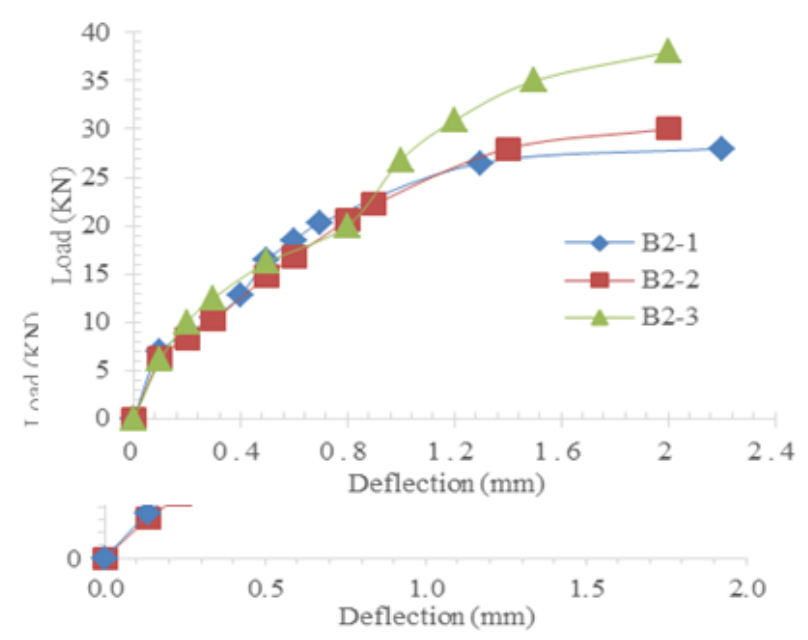

Fig. 4. Load deflection curve of A0 and A5 mixtures

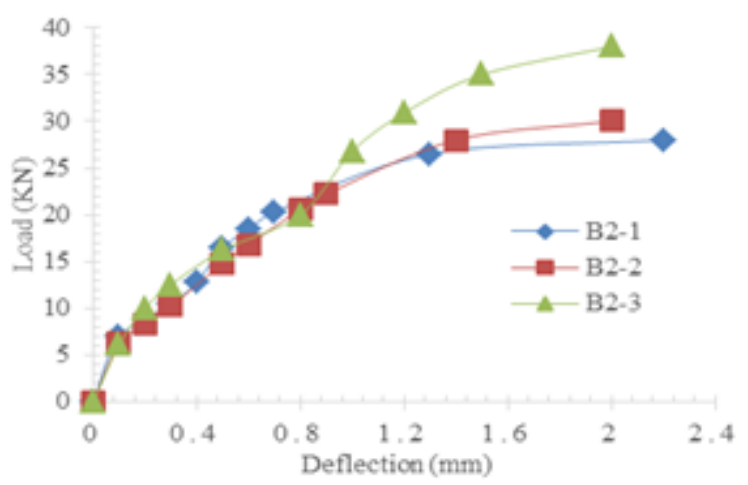

Fig. 5. Load deflection curve of B2 mixtures

\subsection{Moment Curvature}

A comparative moment curvature diagram for slab panels with A5 and B2 mixture with control mixture are shown in Fig $6 \& 7$. The loads were applied gradually in a controlled manner. Demec gauge is used to measure the strain value along the compression and tension $\mathrm{z}$

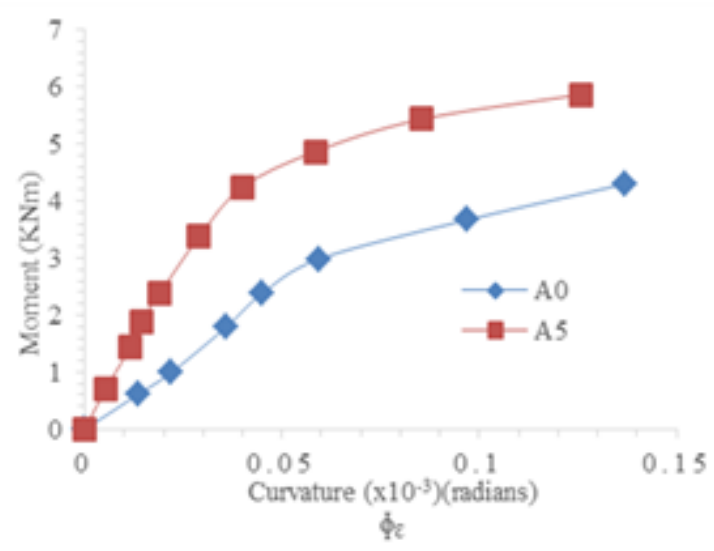


Fig. 6. Moment curvature for slab panels A0 and A5 mixtures

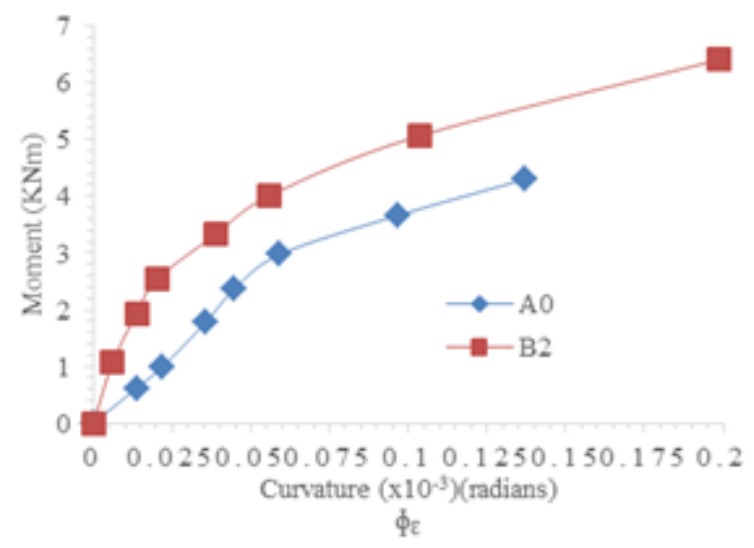

Fig. 7. Moment curvature for slab panels A0 and B2 mixtures

\subsection{Stress-Strain Behaviour of Panels}

Strains on the panels were measured using demec gauge. The load is applied gradually on the panels. The stress-strain behavior of panels for A0 and A5 mixture is shown in Fig 8. The stress-strain behavior of panels of A0 and B2 mixtures is presented in Fig 9.

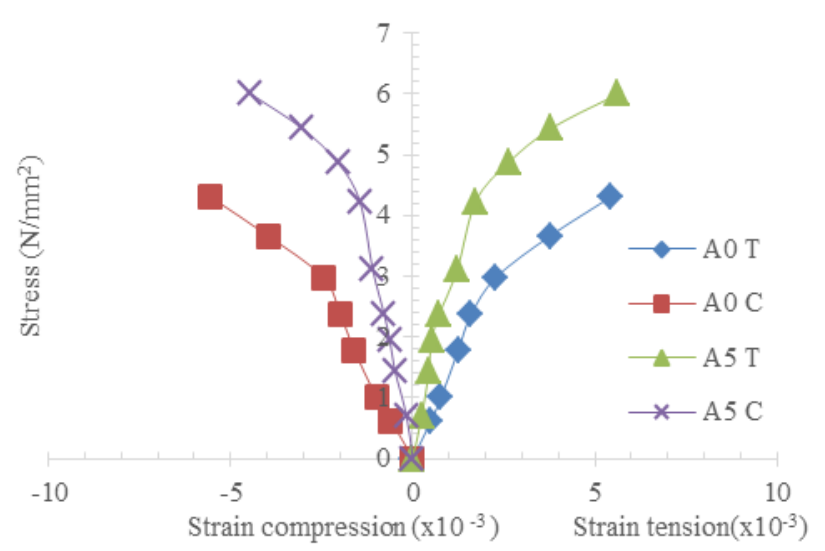

Fig. 8. Stress - Strain behavior of A0 and A5 mixtures

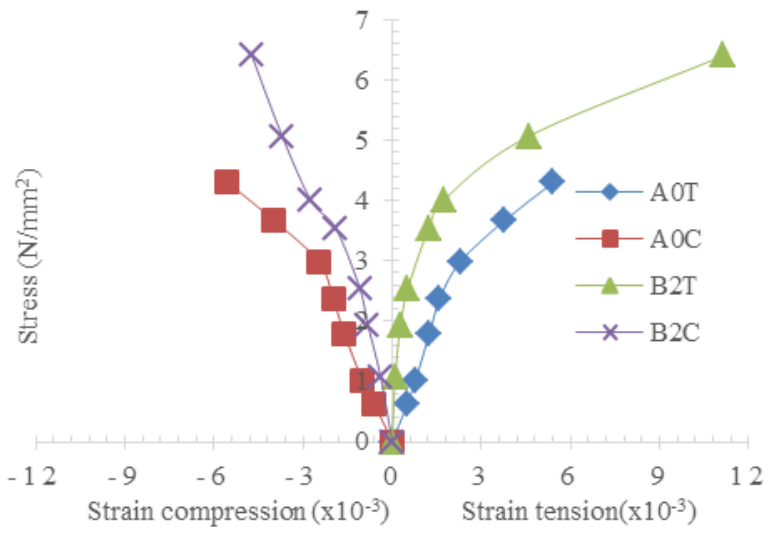

Fig. 9. Stress - Strain behavior of $\mathrm{A} 0$ and $\mathrm{B} 2$ mixtures

\section{Wall Panel}

\subsection{Wall Panel Preparation}

Wall panel were prepared using A0, A5 and B2 mixtures. Wooden moulds of internal dimension $450 \times 300 \times 100 \mathrm{~mm}$ were used. Panels were cast in horizontal direction; one layer of welded wire mesh of grid opening $60 \times 60 \mathrm{~mm}$ was tied with one layer of galvanized mesh of $1 \mathrm{~mm}$ diameter and grid opening of $12 \mathrm{X} 12 \mathrm{~mm}$. the ends of the reinforcement were prepared for one panel. Mortar mixture was prepared, poured into the wooden mould upto height of $15 \mathrm{~mm}$, and well compacted manually and levelled. One layer of combined mesh and galvanized mesh was placed over the mixture allowing equal distance in the sides of the mould. Another reinforcement of combined layer of welded mesh and galvanized mesh was placed above thermocol layer. Mortar mixture again poured into this mesh, compacted properly, and finished smoothly. The panel was demoulded after 24 hours and kept in the curing tank for 28 days.

\subsection{Specimen Preparation}

Panels were taken from the curing tank after 28 days and surfaces were dried. Whitewash was done and specimen details were marked. Markings were done in front and back portion of the panels. Panels were tested in UTM.Plaster of paris was provided at the top and bottom surface of the panels.

\subsection{Uniaxial Load Test on Wall Panels}

Wall panel was kept on UTM bottom vertically by checking verticality and horizontal by using sprit level. I-steel section was placed on the top of the panels to full width of the panels. Dial gauge were fixed to calculate the lateral and horizontal deformation. The test setup for axial load presented in Fig 10.

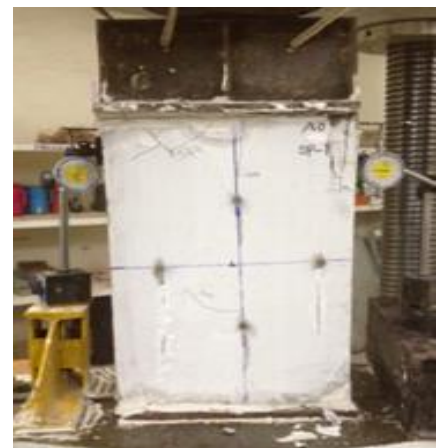

Fig. 10. Axial load test setup

Three panels from each mixtures A0, A5 and B2 were tested by applying UDL on wall panels, vertical, lateral deformation and strain were recorded at different load intervals upto failure load. The compressive strength of panels were represented in Table 6 . The compressive stress strain behavior of panels were shown in Fig 11 and 12.

Table 6: Compressive strength of the panels

\begin{tabular}{|c|c|c|}
\hline Mix id & $\begin{array}{c}\text { Average load } \\
\text { (KN) }\end{array}$ & $\begin{array}{c}\text { Average Compressive strength } \\
\left(\mathbf{N} / \mathbf{m m}^{\mathbf{2}}\right)\end{array}$ \\
\hline A0 & 356.0 & 11.9 \\
\hline A5 & 481.3 & 16.0 \\
\hline B2 & 519.0 & 17.3 \\
\hline
\end{tabular}

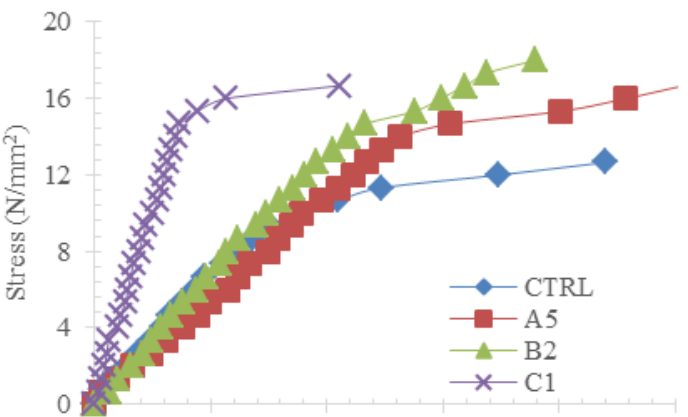

0.00000 .00050 .00100 .00150 .00200 .0025 Horizontal strain 
Fig. 11. Stress Vs. horizontal strain of different types of panels

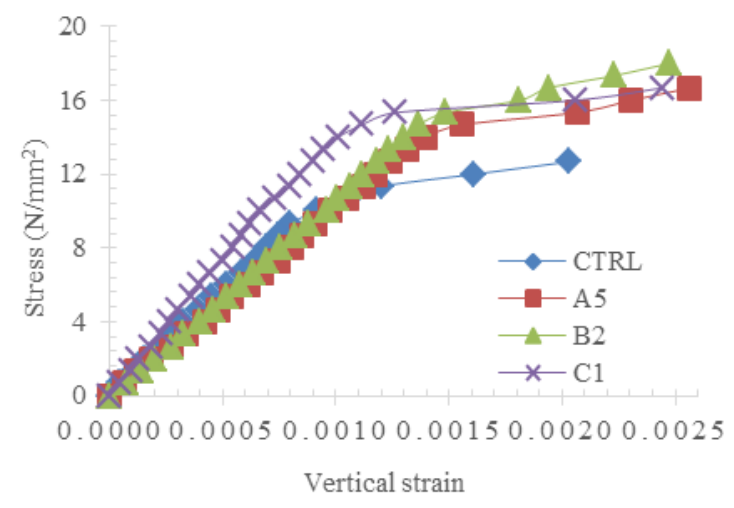

Fig. 12. Stress Vs. vertical strain of different types of panels

\subsection{Load Deflection Curve}

The load versus vertical deflection for the optimized mixtures of ferrocement wall panels was presented in Fig 13 and 14.

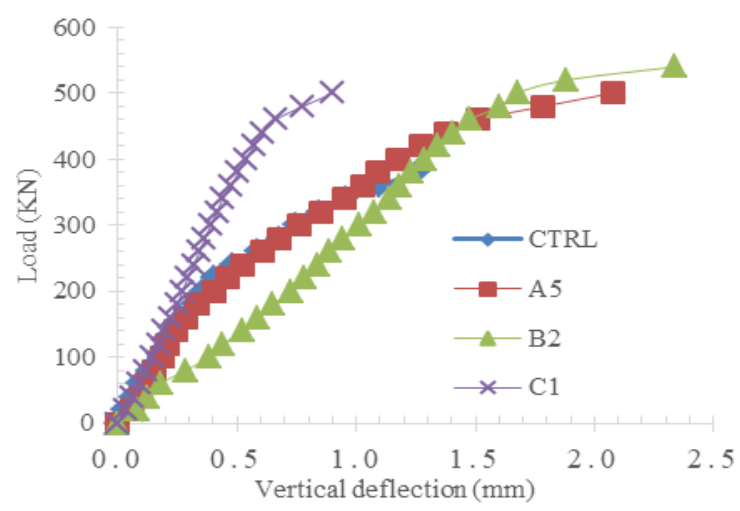

Fig. 13. Load Vs. vertical deflection of different types of panels

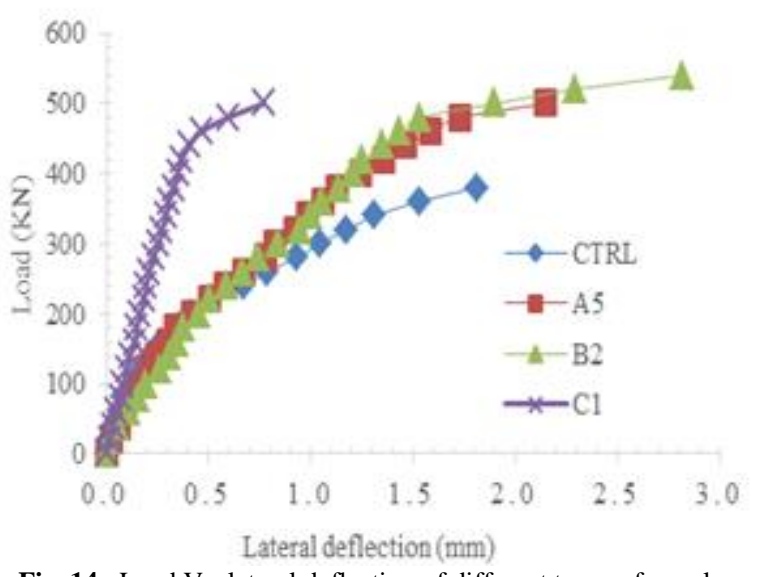

Fig. 14. Load Vs. lateral deflection of different types of panels

\section{Conclusions}

The following conclusions may be drawn from this investigation study:

1. Compared with the sand, specific gravity of copper slag is $31.6 \%$ higher. Water absorption of copper slag is much lesser than the sand. Density of copper slag is $33.4 \%$ higher than the density of sand.

2. Workability of cement mortar increases with increase in percentage of copper slag added to the mortar.

$3.50 \%$ of copper slag could potentially replace for sand in cement mortar mixtures.

4. Almost $8.1 \%$ reduction in water demand at $100 \%$ copper slag replacement in comparison with the control mixture with control mixture at the same workability.

5. By maintaining same workability $100 \%$, substitution of copper slag can be made for sand.

6 . The compressive strength of mortar are comparable to the control mixture upto 50\% copper slag substitution for sand, but they decreased with further increase in copper slag content.

7. Panels prepared with $\mathrm{A} 5, \mathrm{~B} 2$ and $\mathrm{C} 1$ mixtures performances were better compared with control mixture.

8. The sandwich panels with A5 and B2 mixtures yielded higher strength for both flexural and axial loadings than the control mixtures.

9. Crack pattern of the flexural panels and wall panels were compared with the crack pattern of control mixture.

10. This overall investigation indicates that performance of sandwich ferrocement panels, which can be used in construction merits. Therefore, further research work needs to be conducted as well through the economic feasibility.

\section{Acknowledgements}

I would like to express my sincere thanks to Ultra tech for sponsoring cement bags to perform this project.

\section{References}

[1] Brindha D and Nagan S. (2011), Durability studies on copper slag admixed concrete, Asian journal of civil engineering (Building and housing), Vol.12, NO. 5, pp 563-578.

[2] Ezzat H. Fahmy, Yousry B. Shaheen, Mohamed N. AbouZeid and Hassan Gaafar (2004), Ferrocement sandwich and cored panels for floor and wall construction, 29th conference on our world in concrete and structures, pp 245-252.

[3] Khalifa S. Al-Jabri, Makoto Hisada, Salem K. Al-Oraimi and Abdullah H. Al-Saidy.(2009), Copper slag as sand replacement for high performance concrete,Cement and concrete composites 31 (2009), pp 483-488.

[4] Khalifa S. Al-Jabri, Makoto Hisada, Salem K. Al-Oraimi and Abdullah H. Al-Saidy.( 2009), Performance of high strength concrete made with copper slag as a fine aggregate, construction and building materials 23 (2009), pp 2132-2140.

[5] Khalifa S. Al-Jabri, Abdullah H. Al-Saidy and RamziTaha ( 2011), Effect of copper slag as a fine aggregate on the properties of cement mortars and concrete, construction and building materials 25 (2011), pp 933-938.

[6] MadinaSaheb S and Prakash Desayi (1989), Ultimate strength of RC wall panels in one-way in-plane action, journal of structural engineering, Vol. 115, No.10, pp 2617-2630.

[7] MeenakshiSundarvizhi S and Illangovan R (2011), Performance of copper slag and ferrous slag as partial replacement of sand in concrete, international journal of civil and structural engineering, Vol.1, No.4, pp 918-927.

[8] MostafaKhanzadi and Ali Behnood. (2009), Mechanical properties of high-strength concrete incorporating copper slag as coarse aggregate, construction and building materials 23 (2009), pp 2183 2188.

[9] Nagesh .M.Kulkarni and Gaidhankar (2013), Analysis and design of ferrocement panels an experimental study, international journal of inventive engineering and services(IJIES), ISSN: 2319-9598, Vol.1, Issue-5.

[10] Nataraja M.C, Chandan G.G and Rajeeth T.J (2014), Flow properties of cement mortar using copper slag as fine aggregate, journal of civil engineering technology and research, Vol.2, pp 23-31.

[11] Restrepo J.I and Park R. (1996), Test on connections typical of low rise precast reinforced concrete buildings in New Zealand, Eleventh world conference on earthquake engineering, paper no. 824 .

[12] Saleem M.A and Ashrai M. (2008), Low cost earthquake resistant ferrocement small house, Pak.J. Engg and appl.Sci, Vol.2, pp 59-64

[13] Wei wu, Weide Zhang and Guowei Ma. (2010), "Optimum content of copper slag as a fine aggregate in high strength concrete", materials and design 31, pp 2878-2883.

[14] Zakaria Hossain Md, RokonuzzamanMd and Sohji Inoue. (2005), "Flexural behavior of cement composites panels reinforced with 
different types of meshes", 30th conference on our world in concrete and structures, 23-24August 2005, Singapore. 